\title{
Lung cancer findings from the NIOSH study of United States cadmium recovery workers:
}

\section{a cautionary note}

\author{
Tom Sorahan, Robert Lancashire
}

Cancer mortality among workers from a United States cadmium recovery factory has been investigated by a number of authors ${ }^{1-6}$ and the two most recent reports, ${ }^{56}$ which reached very different conclusions regarding lung cancer risks after occupational exposure to cadmium, were reviewed by Doll. ${ }^{7}$ This review noted that "these studies are of greater interest than the size of the cohort might imply, because of the detailed data that the investigators were able to secure about the levels of cadmium to which the workers were exposed". The purpose of this note is to highlight two problems, possibly serious, regarding the quality of the job history data collected by Thun et $a l^{3}$ for a study carried out under the auspices of the National Institute of Occupational Safety and Health (NIOSH). The estimated cumulative cadmium exposures derived from these data were also analysed by Stayner et $a l^{5}$ and Lamm et al. ${ }^{6}$

The first problem concerns inconsistencies in the definition of the NIOSH job history data. Thun et al stated that personnel records show "in most cases, department or general work area for each period of employment". ${ }^{3}$ General work category 1 (high cadmium exposure) was stated to include production work in sampling, roasting and bag house, mixing, calcine, foundry, and retort departments. Category 2 (medium exposure) included production work in the solution, tankhouse, and pigment departments. The only way of knowing whether a period of employment should be placed in category 1 or in category 2, however, is to know the department. If the department was known, why were departments grouped together when the job exposure matrix was defined in terms of departments and not 'general work categories'? Having reviewed personnel and service records at the plant, the situation seems to be as follows: If the service card indicated "cadmium department labourer" the job entry was placed in category 1 , even though the solution, tankhouse, and pigment departments are as much a part of the 'cadmium department' as roasting, mixing, and calcine. In other words, workers were assumed to be in category 1 employment (high exposure) unless the personnel records indicated something to the contrary.

The second problem concerns the accuracy of the NIOSH job history data. There are two sources of job history data at the Globe plant; sparse information recorded in the personnel and service records and detailed information recorded in the time sheets (about 60 books, some of which are 10 inches thick). The time sheets show for each month (or each fortnight) how many hours each worker spent in different jobs. This information was collected because different jobs attracted different rates of pay. (For example, in 1948, a calcine department workman received US\$1.1825 per hour whereas a solution operator received US $\$ 1.255$ per hour.) One can be confident, human nature being what it is, that these work records are fairly accurate because they are also records of payment. It also seems reasonable to discover that the service and personnel records contain only sparse data on job histories when detailed data were being kept elsewhere. These time sheets, which must represent one of the most detailed collection of job history records available to occupational epidemiologists, have, unfortunately, been ignored by all investigators to date, although the records were microfilmed by NIOSH.

The collection of job history data in terms of departments rather than "general work areas" becomes vitally important in adjusting for any effects of arsenic (arsenic is a known human lung carcinogen ${ }^{8}$ ). High exposure to arsenic was only found in the early stages of the cadmium process-namely, sampling, roasting and bag house, and calcine. Indeed, Thun et al provide results of arsenic measurements from 1973 in which very low exposures were found in the pre-melt (casting, 0.3 $\left.\mu \mathrm{g} / \mathrm{m}^{3}\right)$ and retort departments $\left(1 \cdot 1 \mu \mathrm{g} / \mathrm{m}^{3}\right)$ compared with airborne arsenic concentration ranging from $300-700 \mu \mathrm{g} / \mathrm{m}^{3}$ near the roasting and calcine furnaces in 1950 (about $100 \mu \mathrm{g} / \mathrm{m}^{3}$ in 1979). ${ }^{3}$ Stayner et al concluded that it is "impossible to fully discount the potential influence of arsenic exposure" on the statistically significant dose-response relation that they observed between cumulative cadmium exposure and lung cancer risk, and that "more detailed information would be required to fully evaluate potential confounding by arsenic". ${ }^{5}$

In an attempt to obtain more detailed information for this task, job histories from the microfilmed time sheets are being abstracted in this department. Data from microfilm No 27 (April-August 1949) have been abstracted and entered into a computer file. The file includes detailed job histories for 149 employees who were members of the NIOSH cohort and had been assessed by Thun $e t \mathrm{al}^{3}$ as having some employment history in the relevant period. Job histories were
Requests for reprints to: Dr T Sorahan

Accepted 28 June 1993 
Comparison of detailed job histories for 149 ASARCO employees during the period April-August 1949* with general work categories for the same period as found in the NIOSH database

\begin{tabular}{|c|c|c|c|c|c|}
\hline $\begin{array}{l}\text { Principal department } \\
\text { from time sheets }\end{array}$ & $\begin{array}{l}\text { Estimated cadmium } \\
\text { inhalation exposure }\left(\mathrm{mg} / \mathrm{m}^{3}\right)\end{array}$ & $\begin{array}{l}\text { Genera } \\
\text { NIOSI } \\
\text { cadmiu } \\
\text { high† } \\
(1 \cdot 16)\end{array}$ & $\begin{array}{l}\text { utegories fron } \\
\text { se with weig } \\
\text { ition exposu } \\
\text { medium } \neq \\
(0 \cdot 43)\end{array}$ & $\begin{array}{l}\left.m g / m^{3}\right) \\
\operatorname{low} 5 \\
(0.02)\end{array}$ & Total \\
\hline \multicolumn{6}{|l|}{ Cadmium plant: } \\
\hline Foreman & & 0 & 1 & 0 & 1 \\
\hline Sampling & $1 \cdot 0$ & 2 & 0 & 0 & 2 \\
\hline Crushing & $1 \cdot 0$ & 1 & 0 & 0 & 1 \\
\hline Roasting & $1 \cdot 0$ & 5 & 0 & 0 & 5 \\
\hline Calcine department & 1.5 & 13 & 0 & 0 & 13 \\
\hline Mixers and screeners & 1.5 & 5 & 0 & 0 & 5 \\
\hline Solution & 0.8 & 6 & 6 & 0 & 12 \\
\hline Pigment plant & $0 \cdot 2$ & 2 & 0 & 0 & 2 \\
\hline Tankhouse & 0.04 & 9 & 20 & 0 & 29 \\
\hline Retort & 1.5 & 4 & 1 & 0 & 5 \\
\hline Casting & 0.8 & 10 & 0 & 0 & 10 \\
\hline Weigher and packer & 0.04 & 4 & 0 & 0 & 4 \\
\hline Acid recovery plant & 0.04 & 2 & 4 & $\mathbf{0}$ & 6 \\
\hline Unloading labourer & 0.04 & 1 & 1 & 0 & 2 \\
\hline Lead shop & 0.04 & 6 & 0 & 0 & 6 \\
\hline Thallium shop & 0.04 & 1 & 2 & 1 & 4 \\
\hline Machine shop & 0.04 & 17 & 2 & 0 & 19 \\
\hline Electrical shop & 0.04 & 2 & $\overline{0}$ & 0 & 2 \\
\hline Welders and burners & $1 \cdot 0$ & 4 & 0 & 0 & 4 \\
\hline Carpenter shop & 0.04 & 7 & 1 & 0 & 8 \\
\hline Auto truck & 0.04 & 1 & 3 & 1 & 5 \\
\hline Janitor, laundry, guard & 0.04 & 1 & 1 & 2 & 4 \\
\hline \multicolumn{2}{|l|}{ Total } & 103 & 42 & 4 & 149 \\
\hline
\end{tabular}

${ }^{\star}$ Microfilm 27. + General work categories 1 and 4. $\ddagger$ General work categories 2,5 , and 7. §General work categories 3 and 6 (see Lamm et al ${ }^{6}$ ). |Referred to as "foundry" by Thun et al. ${ }^{3}$

collected in terms of hours worked in some 300 job titles, and each title has been categorised by company personnel into one of the 22 departments shown in the table. The principal department for each worker was chosen as the department in which the most hours were worked (principal departments accounted for some $91 \%$ of all hours worked). The cadmium inhalation exposures for each department are those quoted by Thun et $a l^{3}$ except that the exposure estimates for the tankhouse (a wet process with little inhalation exposure to cadmium) has also been used for non-exposed departments. A value of $1.0 \mathrm{mg} / \mathrm{m}^{3}$ has been tentatively attached to welders and burners on the advice of company personnel. The table shows a comparison of these data with the general work category data and weighted exposure estimates analysed in recent papers. ${ }^{3-6}$

Some limitations of the NIOSH data are already apparent. For example, seven of the eight workers from the carpenter shop, with minimal exposure to cadmium, were classified by Thun et $\mathrm{al}^{3}$ as high exposure workers $\left(1 \cdot 16 \mathrm{mg} / \mathrm{m}^{3}\right)$. All six workers from the lead shop, which is not connected to the cadmium process, were also placed in the high cadmium exposure category, as were all four of the weighers and packers from the cadmium plant. Nine of the tankhouse employees were incorrectly placed in general work category 1 (high cadmium exposure); the remaining 20 were allocated an exposure of $0.43 \mathrm{mg} / \mathrm{m}^{3}$ even though the level of exposure for this department had been estimated to be 0.04 $\mathrm{mg} / \mathrm{m}^{3}$. (This arrangement came about because Thun et $a^{3}$ classified both the solution department $\left(0.8 \mathrm{mg} / \mathrm{m}^{3}\right)$ and the tankhouse department $\left(0.04 \mathrm{mg} / \mathrm{m}^{3}\right)$ as medium exposure departments.) Misclassi- fication was also present for solution workers; six were classified as category 1 and six as category 2.

The table shows that much better job history data are available; data that may be usefully incorporated into future analyses. When data from all the microfilms have been abstracted it will be possible to assess whether misclassification of exposures was differential or non-differential with respect to the deaths from lung cancer. ${ }^{9}$ It will also be possible to determine whether the lung cancer excess is confined to those cadmium workers with higher exposures to arsenic. It is tantalising not to know the full story.

Data abstraction from the GLOBE microfilms is being carried out with a research award from the International Lead Zinc Research Organisation.

1 Lemen RA, Lee JS, Wagoner JK, Blejer HP. Cance mortality among cadmium production workers. Ann $N Y$ Acad Sci 1976;271:273-9.

2 Varner MO. Updated epidemiologic study of American cadmium smelter workers. In: Edited proceedings fourth international cadmium conference, Munich. London: Cadmium Association, 1983:149-51.

3 Thun MJ, Schnorr TM, Smith AB, Halperin WE, Lemen RA. Mortality among a cohort of US cadmium production workers-an update. $f$ Natl Cancer Inst 1985; tion worke

4 Lamm SH. Analysis of mortality studies of Globe, Colorado cadmium workers. In: Edited proceedings fifth international cadmium conference, San Francisco. London: Cadmium Association, 1988:120-3.

5 Stayner LT, Smith R, Thun M, Schnorr T, Lemen RA. A dose-response analysis and quantitative assessment of lung cancer risk and occupational cadmium exposure. Ann Epidemiol 1992;2:177-94.

6 Lamm SH, Parkinson M, Anderson M, Taylor W. Determinants of lung cancer risk among cadmiumexposed workers. Ann Epidemiol 1992;2:195-211.

7 Doll R. Is cadmium a human carcinogen? Ann Epidemiol 1992;2:335-7.

8 International Agency for Research on Cancer. IARC Monographs on the evaluation of the carcinogenic risk of chemicals to humans. Vol 23. Some metals and metallic compounds. Lyon: IARC 1980.

9 Rothman KJ. Modern epidemiology. Boston: Little, Brown 1986. 